\title{
Teaching Approaches and Practices of Student Teachers in Early Childhood Education: A Convergent Mixed Methods Study
}

\author{
Mefharet Veziroglu-Celik ${ }^{1}$, Ibrahim Hakki Acar ${ }^{2}$ \\ ${ }^{1}$ Faculty of Education, Early Childhood Education, Istanbul Medipol University, Istanbul, Turkey \\ ${ }^{2}$ Department of Psychology, Ozyegin University, Istanbul, Turkey \\ Correspondence: Mefharet Veziroglu-Celik, Faculty of Education, Early Childhood Education, Istanbul Medipol \\ University, Istanbul, Turkey.
}

Received: September 18, 2018

Accepted: October 15, $2018 \quad$ Online Published: October 17, 2018

doi:10.11114/jets.v6i11.3634

URL: https://doi.org/10.11114/jets.v6i11.3634

\begin{abstract}
This study examined the teaching approaches and practices of student teachers in early childhood education using a convergent parallel mixed methods design. The participants were 112 student teachers for the quantitative strand and 29 randomly selected student teachers for the qualitative strand of the study. Participants reported on their teaching approaches in the quantitative strand, and video recordings of teaching practices of student teachers were used in the qualitative strand of the study. Quantitative data were analyzed using cluster analyses, and qualitative data were analyzed using an observational coding of behaviors, following that which the quantitative and qualitative results were merged. Cluster analyses showed that student teachers to be categorized into three groups (traditional, constructivist, and mixed) that reflect their teaching approaches. The qualitative analyses from the video recordings consistently showed that student teachers reflected their perceptions of teaching approaches in their practice. Findings from the current study highlight the importance of understanding student teachers' teaching approaches and practices in early childhood.
\end{abstract}

Keywords: student teachers, convergent study, teaching approach, teaching practice

\section{Introduction}

Teaching requires substantial amount of the knowledge, skills and competencies pertaining to content, classroom management, teaching approaches and practices utilized during the teaching in their educational settings. As children experience schooling more often through guidance from teachers, the biggest role in children's academic and social success empowered by teachers, particularly in early childhood (Acar, Hong, \& Wu, 2017; Beteille \& Loeb, 2009; Darling-Hammond, 2003). Taken all these into account, the educational practices and approaches of the teachers constitute the most important component of the education process in early childhood settings. Although teachers evolve their teaching approach and practices as they teach during their careers, teacher training programs at universities are the primary resources to gain knowledge regarding these competencies. From this perspective of importance of the early development of teaching approach and practices, we aimed to explore student teachers' teaching approach and practices while they were receiving training. By doing so, researchers and training practicum providers (e.g., trencher training programs) may learn better which aspects of the programs should be scaffolded so that student teachers will have competence in their practices and approaches once they start their careers in early childhood settings.

\subsection{Practices and Approaches in Early Childhood Education}

With regard to the characteristics of educational practices provided by teachers in early childhood education programs can be defined as developmentally appropriate or developmentally inappropriate, child-centered or teacher-centered, academic or play-based (Stipek, 2011). These categories emerge with the differentiation of teaching approaches and practices provided by teachers (Stipek \& Byler, 2004). Children are seen as active constructors of knowledge in educational practices in which teachers' practices are based on constructivist approach shaped by Piaget's cognitive theory and Vygotsky's socio-cultural development theory. According to these theories, teachers utilizing constructivist approach in their teaching should be in a guiding role in organizing educational settings and activities in a developmentally appropriate way to facilitate children's learning, motivating children to learn and encouraging them to be involved in firsthand experiences in the learning process. According to Vygotsky's socio-cultural theory, teachers are actively responsible 
but this responsibility requires the design of an educational process centering on the child's interests and needs (Stipek, 2004, Ryan, 2007; Vygotsky, 1986; Woolfolk, 2014).

Teachers adopting a constructivist approach in the education process consider children as active learners and offer effective educational activities by encouraging their independent experiences (Pianta, Le Paro, Payne, Cox, \& Bradley, 2002). In addition, teachers should be responsive to children's interests and needs in order to plan the educational process with appropriate activities and materials in accordance with children's development and learning levels to provide constructive feedback during the activities. Teachers' child-centered approach in education practices increases children's motivation to learn, develop their skills to take responsibility as an active learner, increase their ability to start a task, maintain and complete it (Zimmerman \& Cleary, 2009). In order to provide an effective education in early childhood, it is important that the activities offered should be developmentally appropriate which can be seen as supportive of children's holistic developmental domains (e.g., social and language), teachers should create sensitive and warm interactions in the classroom environment and they should provide learning experiences that involve effective stimuli that are supported by a child-centered classroom environment (Pianta, 2011).

In addition to teachers adopting a constructivist approach, there are teachers who adopt a teacher-centered traditional approach in early childhood education. The traditional approach is based on activities selected and planned directly by the teacher and there is a great emphasis on the development of basic academic skills in children. This perspective can often be accompanied by a reduction in play time, and a lack of emphasis on other areas of development other than cognitive and academic development (Bishop-Josef \& Zigler, 2011). The approach that cognitive and academic skills are frontal is more common in regions where children come from a lower socioeconomic status or are at a lower level of development and learning than their peers (Pianta, et al. 2002; Stipek, 2004). It can sometimes be seen that teachers have to adopt a more traditional approach to the education practices in the direction of the educational policies of their country and demands of families (Bodrova \& Leong, 2003; Raver \& Zigler, 2004). However, self-concept and learning motivation of children can be adversely affected by the traditional approach where direct teaching is conducted, activities are directly chosen by teachers, and teachers have less positive encouragement (Dweck \& Master, 2013; Stipek, 2011).

There is a large body of research examining the effects of educational practices on children's learning and development in early childhood education. In these studies, teachers' educational practices and approaches were examined in terms of teachers' behaviors, discipline techniques, social emotional climate in the classroom, child-centered or teacher-centered activities, teacher-child interaction, and it was found that these variables were related to the children's academic outcomes, behavior development in educational process and motivation to learn (Acar et al., 2018; Rimm-Kaufman et al., 2009; McWilliam, Stipek, Feiler, Daniels, \& Milburn, 1995; Scarborough \& Kim, 2003; Kamins \& Dweck, 1999; Justice, Mashburn, Hamre, \& Pianta, 2008; Pianta, La Paro, \& Hamre, 2008). In these studies, classroom environments with childcentered practices and approaches were defined as more effective and qualified, in turn children who were in these classrooms displayed more positive behaviors in the learning processes. Besides there are also studies showed that teachercentered practices and approaches had negative effects on children's behavior rather than constructivist practices and approaches (Burts, Hart, Charlesworth, \& Kirk, 1990, Stipek, Feiler, et al., 1998).

Teachers' educational level, knowledge, educational goals and beliefs influence their instructional practices and teaching approaches (Nelson, 2000; Stipek \& Byler, 1997). Further, there are discrepancies between teachers' views on how they implement teaching practices and how they actually practice these approaches in classroom settings (Palender, 1997). A study linked these inconsistencies to the personal characteristics of teachers and relate them to the training they have received during their pre-service and professional development programs (Goffin \& Day, 1994). Teachers' beliefs about the educational and the instructional practices they offer are shaped during their training process. For this reason, the training of the student-teachers in the process of preparing for the profession should be structured in a way to enable them to refer to the constructivist educational practices when they start their profession (Isikoglu, 2008; Mills, 2007).

Although teachers consider a variety of activities in early childhood education settings, early literacy activities have a predominant place as it has central role in development of academic and social competencies of children (Fleer, 2010; Hart \& Risley, 1991; Schachter, Spear, Piasta, Justice \& Logan, 2016). Early childhood period plays a critical role in the development of early literacy skills and children who are inadequate in these skills have problems in literacy competencies when they start reading and later in educational process (Baydar, et al., 1993; Roberts, Jurgens, \& Burchinal, 2005). In early years of life, children gain these preliminary skills in reading, which helps them develop positive attitudes towards reading, influencing the achievement of both specific and academic experiences (Lawson, 2012).

The development of early literacy skills, vocabulary and reading attitudes of children are influenced by the early literacy practices of their parents, primary caregivers and preschool teachers (Hart \& Risley, 1991; Lawson, 2012; Evan et al., 2000). Literacy activities such as regular book-sharing, storytelling, both in the home environment and in the school environment, and the appropriate and supportive techniques applied during these activities, help children to maximize the 
benefit of these activities. For this reason, it is very important for the teacher to employ effective techniques and the quality interactions with children during the book reading activities. From the perspective of the ecological systems theory of child development, proximal processes such as quality teacher-child interactions within learning activities (e.g., literacy activities) affect children's all areas of development including language development (Bronfenbrenner \& Morris, 2006).

Teaching approaches and practices such as the types of questions; asking open-ended or closed-ended questions, the way teachers' instructional approach; constructivist or traditional during early childhood literacy activities underpin the nature of teacher-child interaction and child outcomes (Riviera et al., 2005; Zucker, Justice, Piasta, \& Kadaravek, 2010). Inferential, predictive, or reasoning questions that the teacher directs to the child during the reading activities improve the children's abstract thinking and help them to develop their cognitive skills (Zucker et al., 2010). Considering the vitality of early literacy development and how teachers implement activities in early childhood education, we utilized student teachers' approaches and practices during early literacy activities in the current study. During these activities we aimed to explore what kind of practices and they utilize and how these practices converge with their perception of teaching approaches they report.

\subsection{The Current Study}

Previous research has been based on solely quantitative (Riviera et al., 2005; Zucker et al., 2010) or qualitative orientation in examining teachers' teaching approaches or their practices. However, a challenge of examining teachers' teaching approaches and their practices is both capturing to what kind of approaches teacher utilize in their teaching and how these approaches are perceived by the teachers. Considering complexity of understating how teachers utilize and perceive their teaching approaches and practices, it may be helpful to collect quantitative data from teachers and qualitative data through live observation during their practices to converge both data resources to understand the underling factors of this complexity. Teachers' teaching approaches and practices.

This mixed method study addresses the student teachers' teaching approaches and practices using a convergent parallel mixed method design in which quantitative and qualitative data were collected in parallel, analyzed separately, and then merged (Creswell, 2014). In the quantitative strand, we used participant-report of their teaching approaches (constructivist or traditional) and cluster analysis to group teachers in these approaches. In the qualitative strand of the study, the open coding of video recordings of participants' teaching practices that were performed with a subgroup of participants to explore specific practices at each cluster determined in the quantitative strand of the study. The reason for collecting both quantitative and qualitative data is to merge their results to explain the characteristics of participants' approaches and practices. See Figure 1 for a depiction of the convergent mixed methods design used.

Research Questions:

- Quantitative research question: What groups of student teachers do exist based upon their teaching approaches?

- Qualitative research question: What kind of practices do student teachers reflect in their teaching activities?

- Mixed-methods research question: To what extent do the quantitative (clusters) and qualitative (observations of teaching practices) results converge?

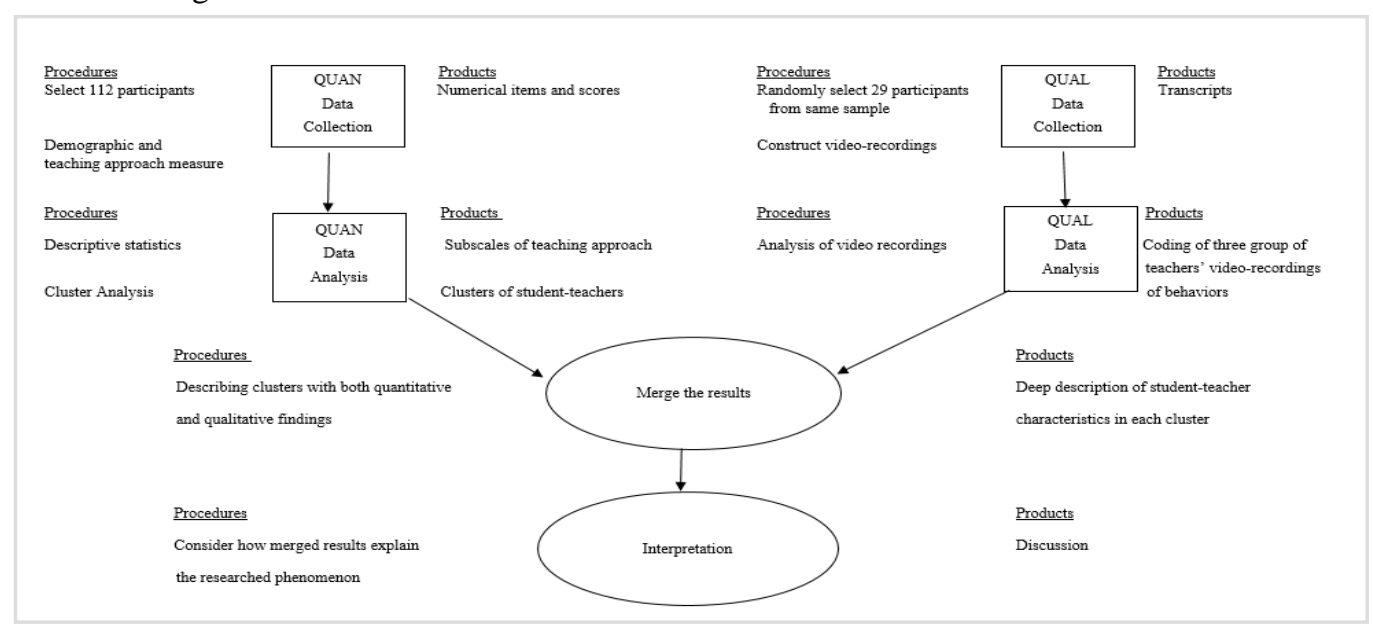

Figure 1. A depiction of the convergent design of student-teachers' teaching approaches and practices in early childhood education

QUAN = Quantitative; QUAL $=$ Qualitative

\section{Methods}




\subsection{The Quantitative Sample}

The participants in the current study were 112 student teachers enrolled in 4-year Early Childhood Education Program at a private university in Turkey. Their age ranged from 18 to 28 years with the mean of $19.44(1.28 S D)$. Of these participants, $8.9 \%$ was male and $91.1 \%$ was female. Informed consent was obtained from all individual participants included in the study before starting the study to align with ethical considerations to implement the study.

\subsection{The Qualitative Sample}

The sample in a qualitative strand of mixed methods research is based on criterion sampling (Creswell, 2014). The criteria for sampling was being involved in the quantitative sample with the video-recordings of their instructional practices during literacy activities. Considering this criteria total of randomly selected 29 student teachers who videotaped their instructional practices during literacy activities with children. As we randomly selected these student teachers, we were unaware of which cluster they might fall into in the quantitative strand of the study. By doing so, we had the opportunity to represent each cluster with different perspectives of teachers when converging the quantitative and qualitative results.

\subsection{Quantitative Data Collection}

Teaching Approaches

We used the Teaching and Learning Conceptions Questionnaire (TLCQ; Chan \& Elliot, 2004) to measure teachers' conceptions about teaching. The TLCQ has been validated in Turkish by Aypay (2011). The questionnaire consists of two subscales such as constructivist and traditional and it is 5-point Likert-type scale from strongly agree to strongly disagree. Higher scores indicate that teachers strongly agree to the item and receive higher scores in constructivist or in traditional subscales. This scale has been used with Turkish pre/in service teachers in early childhood education in previous research (Ucus \& Acar, 2018). The TLCQ is a 20-item questionnaire that is rated on rated on a 5-point Likerttype scale $(1=$ strongly disagree and $5=$ strongly agree $)$. It has two subscales: 12 items tapping the use of a constructivist approach (12 items, e.g., "The focus of teaching is to help students construct knowledge from their learning experience instead of knowledge communication"), and 18 items tapping the use of a traditional approach (8 items, e.g., "Teaching is to provide students with accurate and complete knowledge rather than encourage them to discover it."). The internal consistency for constructivist subscale was .72 (Cronbach's alpha) and traditional subscale was .78.

\subsection{Qualitative Data Collection}

Randomly selected 29 student teachers in the qualitative strand of the study provided video recordings of themselves during their literacy activities. These recordings included book sharing, reading aloud and storytelling activities with the variety of interactive literacy techniques such as using prompts, flannel boards, finger puppets and drawing the story. In these video recordings, student teachers reflected their teaching practices as they provided interactive instruction to the preschool children. Duration of the recordings were ranged from $1.13 \mathrm{~min}$. to $9.36 \mathrm{~min}$. with the mean of $3.89 \mathrm{~min}$.

\subsection{Quantitative Data Analysis}

First, the normality of variables has been examined. Constructivist approach had skewness of $-.74(\mathrm{SE}=.22)$ and kurtosis of -.02 ( $\mathrm{SE}=.45)$; traditional approach had skewness of $.32(\mathrm{SE}=.23)$ and kurtosis of -.11 ( $\mathrm{SE}=.45)$. These two variables were within the accepted range of skewness and kurtosis $(-1.5$ skewness/ kurtosis +1.5 ; Tabachnick \& Fidell, 2013) for normality. Internal consistency of the subscales has also been examined as seen in the methods section.

Next, we ran cluster analyses to identify the groups of student teachers depending on their levels of teaching approaches. Two-step cluster analysis is an exploratory statistical tool for bringing out natural groups within the data (Everitt, Landau, $\&$ Leese, 2001). We used the Bayesian information criterion (BIC; the smaller the better) to define how many clusters are meaningful (Norusis, 2010). In addition, small cluster sizes $(<20 \%)$ are not taken under consideration as they may have no meaning to interpret (Norusis, 2010). Relative distribution and centroids of final clusters are presented.

Lastly, we examined whether first-year and second-year student teachers differed in their constructivist and traditional teaching approaches. Results from the independent $t$ tests showed that there was no significant difference between firstyear and second-year student teachers constructivist and, $t(109)=-1.15, p=.25$ or traditional teaching approaches, $t(109)$ $=-0.98, p=.32$. As there were no significant differences between first-year and second-year student teachers, we did not perform separate analyses for the two groups.

\subsection{Qualitative Data Analyses}

Considering the aim of this research to understand the student teachers' teaching approaches and practices in clusters, students-teachers were grouped according to their clusters from the results of quantitative data (Creswell, 2014). All the video-recordings were watched and simultaneously transcribed by two researchers then the data were organized by 
replacing participants names with IDs to provide confidentiality. Researchers read through all transcripts line by line and add notes to create initial codes. Significant behaviors of student teachers were listed in accordance with the researched phenomenon. Then these behaviors were clustered under each group created in the quantitative strand of the study reflecting participants' teaching approaches. Each group of coding reflecting participants' behaviors during literacy activities was converged with the quantitative results to comprehensively understand the clusters of student-teachers. We employed bracketing process (epoche), setting aside our personal perceptions and ideas while describing the phenomenon and analyzing the data (Creswell, 2013). We considered each coded behavior in qualitative strand of the study to reflect participants' teaching practices. Reliability of the qualitative data was established using prolonged engagement (i.e., spending enough time in the context of the setting and participants to understand the phenomena of interest), which is a strategy for establishing credibility/confidence in qualitative data (Krefting, 1991; Lincoln \& Guba, 1985). Because both researchers spent and engaged in educational activities, this prolonged engagement permitted researchers to establish rapport with participants, in turn trustworthiness of qualitative data.

\section{Results}

\subsection{Converged Results from Quantitative and Qualitative Analyses}

The two-step cluster analysis shows $B I C=171.715$ for Cluster $1 ; B I C=143.281$ for Cluster 2; BIC $=130.469 .622$ for Cluster 3; and $B I C=134.140974$ for Cluster 4. As seen, the BIC starts increasing after Cluster 3, which implies Cluster 3 is the best solution in the two-step cluster analyses. Regarding the sizes of these three clusters, Cluster 1 had $33.3 \%$ of the student teachers, Cluster 2 contained 38.7\%, and Cluster 3 contained 27.9\% (see Figure 2).

\subsection{Characteristics of The Clusters}

As the relevant distribution (see Figure 2) and centroids (see Table 1) showed, student teachers in Cluster 1 (33.3\%) reported average-to-high levels of traditional and lower levels of constructivist teaching approaches. Relative distribution of student teachers in this cluster tend to skew from average to higher scores on traditional teaching approach; hence we named this group as traditional teaching approach.

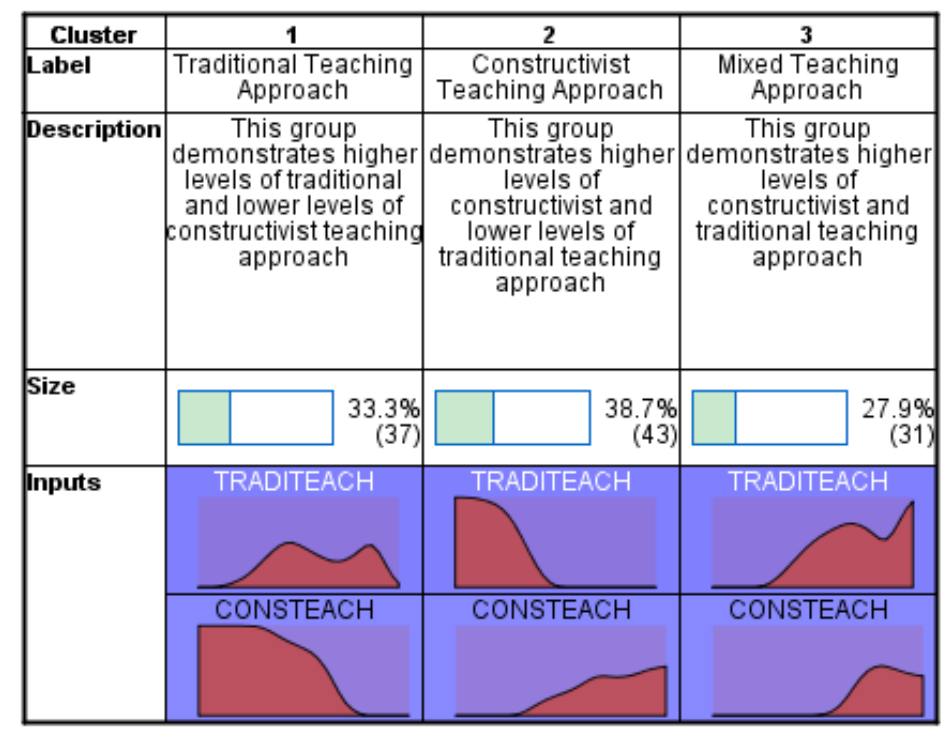

Figure 2. Relative distributions of teaching approaches for the final clusters

Traditeach= Traditional teaching approach, Consteach= Constructivist teaching approach

Table 1. Cluster Centroids

\begin{tabular}{lllll}
\hline Clusters & \multicolumn{2}{l}{ Constructivist Teaching } & \multicolumn{2}{l}{ Traditional Teaching } \\
\cline { 2 - 5 } & $M$ & $S D$ & $M$ & $S D$ \\
\hline
\end{tabular}




\begin{tabular}{lllll}
\hline 1 & 4.24 & .25 & 2.80 & .30 \\
2 & 4.73 & .23 & 2.20 & .22 \\
3 & 4.83 & .13 & 3.03 & .34 \\
Combined & 4.59 & .33 & 2.63 & .45 \\
\hline
\end{tabular}

Qualitative analyses of the video recordings revealed that the student teachers in this group demonstrated some common behaviors during their early literacy activities with children, which could be perceived as traditional approach to teaching. Some of the striking observed common behaviors were using instructional materials (e.g., showing picture of a storyline); however, maximization of utilizing these instructional materials for the favor of the child were lacking. Some other common behaviors observed were: Using close-ended questions during literacy activities, keeping the child passive and instructor was active most of the time, inadequate pre-activity questions for getting the child ready for the activity (e.g., Let's read this book together. Here is the puppet of this book. He will be going to read with us). Engagement between the instructor and the child was fairly lacking and a clear majority of the process was led by the instructor. Instructor's attendance to child's inquiries and needs was lacking even when the child asked questions. Recalling from quantitative results, reflection of student teachers in this group converged with the quantitative results in part because this group of student teachers perceived themselves as traditional in terms of their teaching approach.

In the quantitative strand of the current study, second group of student teachers $(38.7 \%)$ reported constructivist and relatively low levels of traditional teaching approaches. Relative distribution of student teachers in this cluster tend to skew from average to higher scores on constructivist teaching approach; hence we named this group as constructivist teaching approach.

In the qualitative strand of the study, several common behaviors reflecting relatively constructivist approach in their instructions during literacy activities with children were observed. Mainly observed common behaviors were: process was led by the child and instructor was guide rather than dominating the process. Instructors in this group cared about child's perspectives, such that they most of time changed the trajectory of the activity to fit child's interest. They also used open-ended questions managed their voice during book reading to draw attention of the child back to the book when they deviated from the intended activity (e.g., providing dialogic reading 'What do you think this book is about? What would you feel like if you were in her place? Tell me what's happening in this picture'). Engagement between child and instructor was sensitive. Overall, there was a convergence between quantitative and qualitative findings for this group of student teachers. Student teachers reflected their perception of teaching approach they reported in the quantitative strand of the study.

Third group of student teachers reported mixed scores on both traditional and constructivist teaching approaches where both approaches were high on the scale (see Figure 2) in the quantitative strand of the study. This group was interesting in part because they perceived themselves as both traditional and constructivist. This result may reflect that student teachers in this group are not capable of defining their teaching approach yet or they may have misperceived their approach to teaching in early childhood. As this group perceived themselves in both categories at the high end of the spectrum, we named this group as mixed. To understand their mixed perceptions of teaching approach, we qualitatively analyzed their teaching practices as following.

In the qualitative strand of the current study, there were several common behaviors reflecting mixed of instruction-based practices during literacy activities. These behaviors were: Some participants used only close-ended questions, while some others used open-ended questions during the activity. (Using open-ended questions such as 'Do you remember our visit to the zoo? Could you please tell me about what you remember?'” and close-ended questions such as 'What was the name of the child in the story?'”). There were mixed of child-led and instructor-led periods of the activity. There was lack of consistency in their utilization of one teaching approach, which led children disconnected from the activity at times. It appears that student teachers in this group incline to utilize constructivist approach in their teaching; however, the inconsistency occurs in maintaining the approach in the practice. This may be due to lack of knowledge on how to utilize the approach or assurance whether they implement it right or wrong so they switch in between two approaches. We acknowledge that this group is interesting because this might reflect majority of the student teachers in our daily educational activities. We will discuss this in terms of practice in the next section.

\section{Discussion}

This study aimed to examine teaching approaches and practices of student-teachers in early childhood education and whether these approaches converge with their teaching practices. We employed the convergent mixed method design to explore this relation and main findings are discussed below. 
In the quantitative strand of the study, there were three clusters (traditional, constructivist, and mixed) of early childhood student teachers that indicate their different teaching approaches. Student-teachers in traditional group (Cluster 1) perceived themselves as aligned with traditional teaching approaches. On the other hand, student-teachers in constructivist group (Cluster 2) perceived themselves as aligned with constructivist teaching approaches. In addition, third group of student teachers (Cluster 3) perceived themselves as aligned with higher levels of both traditional and constructivist in their teaching.

These findings from the quantitative strand of the study also somewhat converged with the qualitative strand of the study where the findings reflected randomly chosen student teachers' teaching practices. Student-teachers in each group perform in the direction of their teaching approaches they perceived in the quantitative strand. These converged findings are supported by the previous research (Kim, 2017), indicating that student teachers who had more traditional beliefs towards education also adopted the teaching behaviors that reflected these beliefs in their teaching such as such as obsessive teaching (e.g., stuck with one method of teaching and not being flexible). Conversely, a coherent teaching (e.g., being able to adapt teaching approach as a response to demands in the context) is associated with a constructive teaching belief of teacher candidates (Kim, 2013). From theoretical perspective, teachers' educational practices are related to their beliefs regarding education (Bandura, 2006) and professional qualifications that teachers bring to their profession are also one of the most important determinants of classroom practices (Baumert \& Kunter, 2006). An effective educational process, should adopt a constructive teaching approach that centralizes the child's developmental status, needs, and interests. The constructivist approach in early childhood education is considered as developmentally appropriate (Stipek, 2011; Woolfolk, 2014). In turn, constructivist teaching supports child-centered practices which help children improve their important competencies such as perseverance, motivation to learn, and taking responsibility of learning (Zimmerman \& Cleary, 2009). Further, constructivist beliefs that student-teachers have developed during teacher training programs are largely related to their perceptions about teacher efficacy (Kim, 2017). As it indicated in previous study, particularly designed intervention programs targeting constructivist teaching methods during pre-service teacher training programs also tend to change their beliefs towards constructivist direction (Isikoglu, 2008).

There were also student teachers who perceived themselves as traditional in their teaching and reflected this perception in the same direction during their teaching practices. As parallel to previous statement above, student teachers' perception and practices are aligned in traditional group too.

Although we know that utilizing developmentally appropriate practices within the constructivist teaching in early childhood education (Di Santo, Timmons, \& Lenis, 2017; Isikoglu, 2008; Sakellariou \& Rentzou, 2011), student teachers may have difficulty to reflect their approaches and beliefs in their practices. Parallel to this, we found in the current study that student teachers who perceived themselves as nonconstructivist in their teaching approach (e.g., traditional) also reflected this during their instructions. This finding also was aligned with the mixed group of student teacher who had reported themselves as both traditional and constructivists, which also was reflected in their teaching practices. For instance, student teachers in this group sometimes started an activity with open ended questions to draw attention of children to the activity (reflecting constructivist approach) but then switched to close ended questions and teacher-led practices as the activity evolve. This may be due to either unconscious practice that student teachers are not aware of what they implement or lack of knowledge how to utilize instructional tools during activities.

\section{Implications of the Current Study}

Pre-service training programs have important role to student teachers to scaffold their teaching approaches and practices in developmentally appropriate ways and to increase classroom quality so that children can develop and learn better (Barnett, 2004; Bufkin \& Bryde, 1996; Erturk et al., 2014). When teachers are effectively trained, they establish more qualified teacher-child relationships, implement more effective educational activities, exhibit more constructivist approach, and create more qualified classroom environment in developmentally appropriate way (Barnett, 2004; Frede et al., 2009; Veziroglu, 2014; Isikoglu, 2008). However, receiving bachelor's degree or having specific training in early childhood education may not guarantee that teachers could reflect these learnt competencies in their real-life activities. There is the study indeed showing that the educational levels of teachers in early childhood education did not influence on teaching activities of teachers (Early et al., 2007). For this reason, it is important to ensure that the content of the teachers' pre-service training is high quality and includes not only theoretical knowledge but also hands-on experiences that will enable them to apply the theory into practice. In such a training process, it is necessary to ensure that the studentteachers go through an active learning process, in which they organize their knowledge, and to construct their own knowledge and skills in teaching through guidance and feedbacks they receive from their faculty or supervisors.

Understanding student teachers' teaching approaches may provide information to faculty members to design programs or subjects targeting improvement of student teachers' constructivist teaching competencies. In this developmental process, all the academic staff working in the program should design the course contents with a common approach and especially 
the student-teachers should receive practical work to develop their teaching skills. Today, one of the most important indicators determining the level of development of a country is seen as investing in human capital (Heckman, 2000). Undergraduate programs for teacher education are required to provide a training process in which knowledge of early childhood development and learning as well as teaching skills are taught (Bowman, 2011). Thus, it can be ensured that in the early childhood period, which is the most crucial period of human life in terms of skills acquisition, the educators can be competent educators who can adapt children from a traditional educational approach to a dynamic, flexible and adaptable to the conditions of children and age.

\section{Limitations and Future Directions}

When interpreting the findings of this study one should consider following points. First, we had a small sample size consisting of two classes of student-teachers which may have affected determining group sizes and numbers in cluster analyses. Future study should recruit more student teachers to overcome this issue. Second, we collected data only at one time point which cannot reflect the change in practices and approaches of student teachers. Researchers in future studies can utilize longitudinal data collection to see change over time. Although our results cannot be generalized to wider group of student-teachers in early childhood education due to these limitations, our findings shed light on researchers, academicians, and educators about the improvement of the early childhood teacher training programs and the quality of teachers. Student-teachers who believe that constructivist approach is necessary for young children's learning and who are able to reflect this approach in their practice, will have a stronger start to the profession if they get an opportunity during their pre-service teacher training program.

\section{Acknowledgements}

The first version of this study was presented at the 1st International Congress on New Horizons in Education and Social Sciences, April 9-11, 2018 Istanbul, Turkey.

\section{References}

Acar, I. H., Hong, S. Y, \& Wu, C. (2017). Examining the Role of Teacher Presence and Scaffolding in Preschoolers' Peer Interactions. European Early Childhood Education Research Journal, Advance Online Publication. https://doi.org/10.1080/1350293X.2017.1380884

Aypay, A. (2011). The adaptation of the Teaching Learning Conceptions Questionnaire and its relationships with epistemological beliefs. Kuram ve Uygulamada Eğitim Bilimleri, 11, 7-29.

Baydar, N., Brooks-Gun, J., \& Furstenberg, F. F. (1993). Early warning signs of functional illiteracy: Predictors in childhood and adolescence. Child Development, 64(3), 815-829. https://doi.org/10.2307/1131220

Beteille, T., \& Loeb, S. (2009). Teacher quality and teacher labor markets. In G. Sykes, B. Schneider and D. N. Plank (Eds.). Handbook of education policy research, 596-613. NewYork: American Educational Research Association.

Bufkin, L. J., \& Bryde, S. (1996). Implementing a constructivist approach in higher education with early childhood educators. Journal of Early Childhood Teacher Education. 17(2), 58-65. https://doi.org/10.1080/1090102960170207

Chan, K. W., \& Elliott, R. G. (2004). Relational analysis of personal epistemology and conceptions about teaching and learning. Teaching and Teacher Education, 20, 817-831. https://doi.org/10.1016/j.tate.2004.09.002

Creswell, J. W. (2013). Qualitative inquiry and research design: choosing among five approaches. Thousand Oaks, CA: Sage Publications.

Creswell, J. W. (2014): Research Design. Qualitative, Quantitative and Mixed Methods Approaches. Fourth ed. Lincoln: Sage Publications

Darling-Hammond, L. (2003). Keeping good teachers: What leaders can do. Educational Leadership, 60, 8, 5-13.

Everitt, B. S., Landau, S., \& Leese, M. (2001). Cluster analysis (4th ed.). London, UK: Edward Arnold Publishers Ltd.

Fleer, M. (2010). Early learning and development: Cultural-historical concepts in play. Melbourne: Cambridge University Press. https://doi.org/10.1017/CBO9780511844836

Goffin, S., \& Day, D. (1994). New perspectives in early childhood teacher education: Bringing practitioners into the debate. New York: Teachers College Press.

Krefting, L. (1991). Rigor in qualitative research: The assessment of trustworthiness. The American Journal of Occupational Therapy, 43(3), 214-222. https://doi.org/10.5014/ajot.45.3.214

Lawson, K. (2012). The real power of parental reading aloud: exploring the affective and attentional dimensions. Australian Journal of Education 56(3), 257. https://doi.org/10.1177/000494411205600305 
Lincoln, Y. S., \& Guba, E. G. (1985). Naturalistic Inquiry. Beverly Hills, CA: Sage.

Nelson, R. F. (2000). Personal and environmental factors that influence early childhood teachers' practices. Journal of Instructional Psychology, 27, 95-103.

Norusis, M. J. (2010). Cluster analysis. In M. Norušis (Ed.), PASW statistics 18 statistical procedures companion (pp. 361-391). Upper Saddle River, NJ: Prentice Hall.

Pelander, J. (1997). My transition from conventional to appropriate practices in the primary grades. Young Children, $52(7), 19-25$.

Pianta, R. C. (2011). A degree is not enough: Teachers need stronger and more individualized professional development supports to be effective in the classroom. In E. Zigler, W.S., Gilliam and W.S. Barnett (Eds.). The Pre-k Debates, 64-68. Maryland: Brooks Publishing.

Roberts, J., Jurgens, J., \& Burchinal, M. (2005). The Role of Home Literacy Practices in Preschool Children's Language and Emergent Literacy Skills. Journal of Speech, Language, and Hearing Research. 48(2), 345-359. https://doi.org/10.1044/1092-4388(2005/024)

Stipek, D. (2011). Classroom practices and children's motivation to learn. In E. Zigler, W.S., Gilliam and W.S. Barnett (Eds.). The pre-k debates, 98-104. Maryland: Brooks Publishing.

Stipek, D., \& Byler, P. (1997). Early childhood education teachers: Do they practice what they preach? Early Childhood Research Quarterly. 12, 305-325. https://doi.org/10.1016/S0885-2006(97)90005-3

Stipek, D., \& Byler, P. (2004). The early childhood classroom observation measure. Early Childhood Research Quarterly. 19, 375-397. https://doi.org/10.1016/j.ecresq.2004.07.007

Tabachnick, B. G.,, \& Fidell, L. S. (2013). Using multivariate statistics (6th ed.). Boston, MA: Pearson.

Ucus, S. \& Acar, I. H. (2018). The association between teachers' innovativeness and teaching approach: The mediating role of creative classroom behaviors. Social Behavior and Personality, Advance Online Publication. https://doi.org/10.2224/sbp.7100

Zeichner, K., \& Tabachnik, R. (1981). Are the effects of university teacher education washed out by school experience? Journal of Teacher Education 32 (1), 7-11. https://doi.org/10.1177/002248718103200302

Zimmerman, B. J., \& Cleary, T. J. (2009). Motives to self-regulate learning: A social cognitive account. In K. R. Wentzel and A. Wigfield (Ed.). Handbook of motivation at school, 247-265. New York: Routledge.

Zucker, T. A., Justice, L. M., Piasta, S. B., \& Kadaravek, J. N. (2010). Preschool teachers' literal and inferential questions and children's responses during whole-class shared reading. Early Childhood Research Quarterly, 25(1), 65-83. https://doi.org/10.1016/j.ecresq.2009.07.00

\section{Copyrights}

Copyright for this article is retained by the author(s), with first publication rights granted to the journal.

This is an open-access article distributed under the terms and conditions of the Creative Commons Attribution license which permits unrestricted use, distribution, and reproduction in any medium, provided the original work is properly cited. 